BMJ Open

Diabetes

Research

\& Care

\section{Neonatal amygdala microstructure mediates the relationship between gestational glycemia and offspring adiposity}

To cite: Cai S, Aris IM Yuan WL, et al. Neonatal amygdala microstructure mediates the relationship between gestational glycemia and offspring adiposity. BMJ Open Diab Res Care 2021;9:e001396. doi:10.1136/ bmjdrc-2020-001396

- Supplemental material is published online only. To view, please visit the journal online (http://dx.doi.org/10.1136/ bmjdrc-2020-001396).

Received 27 March 2020 Revised 24 March 2021 Accepted 3 April 2021
Check for updates

(C) Author(s) (or their employer(s)) 2021. Re-use permitted under CC BY-NC. No commercial re-use. See rights and permissions. Published by BMJ.

For numbered affiliations see end of article.

Correspondence to Dr Anqi Qiu; bieqa@nus.edu.sg

\section{ABSTRACT}

Introduction To determine if variations in the neonatal amygdala mediate the association between maternal antenatal glycemia and offspring adiposity in early childhood.

Research design and methods 123 non-obese pregnant women with no pregnancy complications aside from gestational diabetes underwent a $75 \mathrm{~g}$ 2-hour oral glucose tolerance test at 26-28 weeks' gestation. Volume and fractional anisotropy (FA) of the neonatal amygdala (517 days old) were measured by MRI. The Body Mass Index (BMI) z-scores and sum of skinfold thickness (subscapular and triceps) of these children were tracked up to 60 months of age (18, 24, 36, 48, 54 and 60 months). Results Maternal fasting glucose levels were positively associated with the offspring's sum of skinfold thickness at age 48 months ( $\beta=3.12,95 \% \mathrm{Cl} 0.18$ to $6.06 \mathrm{~mm}$ ) and 60 months ( $\beta=4.14,95 \% \mathrm{Cl} 0.46$ to $7.82 \mathrm{~mm}$ ) and $\mathrm{BMl}$ z-scores at 48 months ( $\beta=0.94,95 \% \mathrm{Cl} 0.03$ to 1.85$), 54$ months ( $\beta=0.74,95 \% \mathrm{Cl} 0.12$ to 1.36$)$ and 60 months ( $\beta=0.74,95 \% \mathrm{Cl} 0.08$ to 1.39). Maternal fasting glucose was negatively associated with the offspring's FA of the right amygdala ( $\beta=-0.019,95 \% \mathrm{Cl}-0.036$ to -0.003$)$. Right amygdala FA was negatively associated with the sum of skinfold thickness in the offspring at age 48 months ( $\beta=-56.95,95 \% \mathrm{Cl}-98.43$ to $-15.47 \mathrm{~mm}$ ), 54 months ( $\beta=-46.18,95 \% \mathrm{Cl}-88.57$ to $-3.78 \mathrm{~mm}$ ), and 60 months $(\beta=-53.69,95 \% \mathrm{Cl}-105.74$ to $-1.64 \mathrm{~mm})$. The effect sizes mediated by right amygdala FA between fasting glucose and sum of skinfolds were estimated at $\beta=5.14$ (95\% Cl 0.74 to 9.53$) \mathrm{mm}(\mathrm{p}=0.022), \beta=4.40(95 \% \mathrm{Cl}$ 0.08 to 8.72$)(p=0.049) \mathrm{mm}$ and $\beta=4.56(95 \% \mathrm{Cl}-0.17$ to $9.29) \mathrm{mm}(\mathrm{p}=0.059)$ at 48,54 and 60 months, respectively. Conclusions In the offspring of non-obese mothers, gestational fasting glucose concentration is negatively associated with neonatal right amygdala FA and positively associated with childhood adiposity. Neonatal right amygdala FA may be a potential mediator between maternal glycemia and childhood adiposity.

\section{INTRODUCTION}

Obesity and gestational diabetes pose major public health challenges as their prevalence

\section{Significance of this study}

What is already known about this subject?

- Maternal hyperglycemia increases risk of offspring adiposity later in life.

What are the new findings?

- Maternal fasting glucose was negatively associated with the offspring's fractional anisotropy (FA) of the right amygdala, a brain region that regulates appetite and feeding behavior.

- Right amygdala FA was negatively associated with sum of skinfold thickness in the offspring at age 48 , 54 and 60 months.

- Mediation analyses suggest neonatal right amygdala FA may be a potential mediator between maternal glycemia and childhood adiposity.

How might these results change the focus of research or clinical practice?

- This is a novel pathway by which maternal hyperglycemia can potentially contribute to subsequent risk of offspring adiposity.

increase rapidly worldwide. ${ }^{12}$ Maternal hyperglycemia not only results in excessive fetal growth ${ }^{3}$ but can also predispose the offspring to risk of adiposity later in life. ${ }^{4-7}$ Indeed, our study group has previously shown that antenatal fasting glucose was significantly associated with offspring adiposity ${ }^{8}$ among non-obese women, which was consistent with previous findings. ${ }^{9}$ Metabolic imprinting and epigenetic modification have been suggested to contribute to childhood obesity. ${ }^{10}{ }^{11}$ Some studies have used MRI in neonates and infants to study offspring adiposity. One study observed that the volume of brain region like the insula is inversely related to percentage body fat in babies from birth to 6 months postpartum, ${ }^{12}$ while another reported negative 
association between maternal adiposity (a risk factor of offspring adiposity) and global as well regional fractional anisotropy (FA) in neonates. ${ }^{13}$ However, little research has examined if the brain regions which regulate appetite and feeding behavior may play a role in offspring adiposity associated with maternal glycemia.

Food intake is regulated by hormones ${ }^{14}$ and neural signals, with most studies focusing on the hypothalamus. ${ }^{15} 16$ Animal studies have shown that amygdala lesions can affect appetite, food intake (ie, hyperphagia) and weight gain. ${ }^{17-20}$ Many human studies support that the amygdala may be an important site for food intake regulation $^{21}$ and may be linked to obesity. ${ }^{22-24}$ Children who exhibited greater brain response in anticipation of food relative to money, within the appetite-related regions such as the amygdala, also ended up having more food intake. ${ }^{25}$ Graham et $a l^{26}$ demonstrated that greater neonatal right amygdala volume and connectivity were associated with lower impulse control for a snack delay task at 2 years of age. Indeed, the amygdala volume has been previously linked to preference for fat intake in young adults ${ }^{27}$ as well as Body Mass Index (BMI) in young adults ${ }^{28}$ and children. ${ }^{23}{ }^{24}$ Functional MRI (fMRI) of obese children demonstrated hyper-responsiveness to food rewards in their amygdala compared with normalweight children. ${ }^{29}$ Schur $e t a l^{0}$ showed that obese children (9-11 years old) with greater reduction in brain activity in the appetite-processing brain regions (including the amygdala), when shown visual cues of high calorie foods, had greater BMI z-score reduction. Others have observed increased amygdala connectivity with the ventromedial prefrontal cortex in lean individuals compared with obese adult participants. ${ }^{31}$ The amygdala is susceptible to maternal environment during early development. ${ }^{32-35}$

However, to date, most studies have emphasized on peripheral metabolism, with little focus on the possibility that in utero maternal effects may be associated with neural mechanisms that regulate energy imbalances associated adiposity. Maternal hyperglycemia has been shown to have long-term effects in the offspring neurodevelopment,${ }^{36}{ }^{37}$ with a lot of focus on memory function in infants ${ }^{38-40}$ due to the pathophysiology of maternal hyperglycemia (fetal hyperglycemia, fetal hypoxemia and iron deficiency). ${ }^{41}$ Gestational diabetes has been linked to increased fetal hypothalamic activation towards glucose $^{42}$ and slower fetal postprandial brain responses. ${ }^{43}$ Maternal insulin sensitivity, in the absence of gestational diabetes, was also associated with slower fetal brain responses. ${ }^{44}$ Animal studies showed that regions of the brain, such as the striatum and hippocampus, are vulnerable to prenatal iron deficiency. ${ }^{45}{ }^{46}$ However, to the best of our knowledge, little is known about maternal glycemia and how it affects neonatal amygdala. In this study, we examined if variations in the neonatal amygdala, in terms of its volume and FA, mediate the association between maternal glycemia and offspring adiposity. The amygdala volume is a measurement of amygdala size, while FA is used to characterize the microstructure organization of the amygdala. ${ }^{47}$ We will focus on offspring of nonobese women, as we have previously shown that maternal fasting glucose and offspring adiposity are significantly associated in these women. ${ }^{8}$ It has been suggested that the effect of maternal glycemia on offspring adiposity is pronounced in non-obese women as maternal obesity shares common biological pathways with hyperglycemia, and presence of maternal obesity may attenuate the association between maternal glycemia and offspring adiposity. ${ }^{48} 49$ We hypothesize that higher antenatal fasting blood glucose levels may be associated with decrease in volume and FA of the neonatal amygdala, which mediate the positive association between maternal glycemia and offspring adiposity in non-obese mothers. We did not hypothesize that there will be any association between 2-hour postoral glucose tolerance test (OGTT) glucose levels and offspring adiposity measures, in view of earlier null findings in the first 3 years of life, by our study group. ${ }^{8}$ This study benefited from the unique opportunity to assess neonatal brain structure at birth and a prospective, longitudinal follow-up of growth.

\section{RESEACH DESIGN AND METHODS}

\section{Participants}

Pregnant women were recruited in their first trimester from the KK Women's and Children's Hospital and National University Hospital in Singapore between June 2009 and September 2010 to participate in the Growing Up in Singapore Towards Healthy Outcomes birth cohort study. ${ }^{50}$ The children were born either at KK Women's and Children's Hospital or National University Hospital between November 2009 and May 2011.

Recruitment of neonates for MRI was previously described ${ }^{51}$ Neonatal brain MRI was done between 5 and 17 days after birth in 189 singleton, naturally conceived neonates ${ }^{52}$ who all went through the T2-weighted MRI scans. A subset of 124 neonates had diffusor tensor imaging (DTI) scans. Participants with poor image quality were excluded due to large head motion that caused misalignment across slices in T2-weighed MRI and signal loss in DTI (T2-weighted scans: $n=7$, DTI: $n=2$ ). Twenty-one neonates were excluded because they were part of multiple birth and/or had a gestational age of $<37$ weeks, birth weight of $<2500 \mathrm{~g}$, a 5 min Apgar score of $<9$, born to mothers with pregnancy complications other than gestational diabetes (eg, pre-eclampsia, intrauterine growth retardation and type II diabetes). Eight were excluded because they did not have antenatal maternal blood glucose data, and another 30 neonates were excluded as their mothers had a first trimester BMI of $\geq 30 \mathrm{~kg} / \mathrm{m}^{2}$. A total of 123 mother-child dyads (T2-weighted: $n=123$, DTI: $n=89$ ) were included in this analysis. All this information is summarized in online supplemental figure 1 .

\section{Oral glucose tolerance test}

At 26-28 weeks' gestation, all the women who came for the clinic visit were offered the $75 \mathrm{~g}$ OGTT, after overnight 
fasting. Blood glucose levels were measured at fasting and 2-hour postglucose test. The 1999 WHO diagnostic criteria $^{53}$ were used to diagnose gestational diabetes mellitus (GDM): $\geq 7.0 \mathrm{mmol} / \mathrm{L}$ for fasting glucose and/ or $\geq 7.8 \mathrm{mmol} / \mathrm{L}$ for 2 hour post-glucose. Women diagnosed with GDM were treated as per standard hospital protocol.

\section{MRI acquisition and analysis}

MRI acquisition in neonates was previously detailed in Qiu et al. ${ }^{52}$ In brief, neonates underwent fast spin-echo T2-weighted MRI and single-shot echo-plan DTI scans using a 1.5-Tesla GE scanner (GE Healthcare) at the KK Women's and Children's Hospital between 5 and 17 days after birth. The neonates were scanned while they were asleep and immobilized using an immobilization bag, without any sedation. The imaging protocols were (1) fast spin-echo T2-weighted MRI (repetition time $(\mathrm{TR})=3500 \mathrm{~ms}$, echo time $(\mathrm{TE})=110 \mathrm{~ms}$, field of view $(\mathrm{FOV})=256 \times 256 \mathrm{~mm}$, matrix size $=256 \times 256,50$ axial slices with $2 \mathrm{~mm}$ thickness) and (2) single-shot echoplanar DTI $\left(\mathrm{TR}=7000 \mathrm{~ms}\right.$, TE $=56 \mathrm{~ms}$, flip angle $=90^{\circ}$, FOV $=200 \times 200 \mathrm{~mm}$, matrix size $=200 \times 200,40-50$ axial slices with $3 \mathrm{~mm}$ thickness, 19 diffusion-weighted images (DWIs) with $\mathrm{b}=600 \mathrm{~s} / \mathrm{mm}^{2}$; one baseline image with $\mathrm{b}=0 \mathrm{~s} / \mathrm{mm}^{2}$ ). For T2-weighted MRI, 50 axial slices with $2 \mathrm{~mm}$ thickness were acquired parallel to the anteriorposterior commissure line. Two T2-weighted images were acquired per subject. For DTI, 40-50 axial slices with $3 \mathrm{~mm}$ thickness were acquired parallel to the anteriorposterior commissure line. Nineteen DWIs with $\mathrm{b}=600 \mathrm{~s}$ / $\mathrm{mm}^{2}$ and 1 baseline with $\mathrm{b}=0 \mathrm{~s} / \mathrm{mm}^{2}$ were obtained.

The delineation of the amygdala was done automatically using Markov random field (MRF) ${ }^{54}$ We also randomly selected 20 T2-weighted MRI datasets for manual delineation, and the intraclass correlation was 0.77 . The leaveone-out validation approach was also used to confirm the MRF accuracy of the amygdala segmentation, and the accuracy was found to be 0.75 . The volume of the amygdala was calculated by multiplying the number of voxels in the structural mask and the image resolution.

The DTI analysis was described in detail previously. ${ }^{35}$ Briefly, geometric distortion of the DTI due to B0-susceptibility differences across the brain was corrected as per Huang et $a l .{ }^{55}$ The diffusion tensor was derived by multivariate least-squares fitting. FA was computed based on the three eigenvalues of the tensor. The mean FA was calculated within the amygdala mask for individual participants when the amygdala mask in the T2-weighted images was applied.

\section{Child anthropometric measurements}

All child anthropometric measurements were obtained as previously described. ${ }^{56}$ The child's weight and height were measured at ages 18, 24, 36, 48, 54 and 60 months (online supplemental figure 1). Sex-specific and agespecific BMI z-scores were derived using weight measurements and either length at 18 and 24 months or height measurements from 36 months onwards, with the WHO Anthro macro V.3.2.2. ${ }^{57}$ Skinfold thicknesses (triceps and subscapular) were measured at birth and at 18, 24, 36, 48, 54 and 60 months using Holtain skinfold calipers (Holtain, Crymych, UK). The sum of skinfold is the summation of triceps and subscapular skinfold thickness.

\section{Additional data}

Demographic data such as ethnicity, maternal age and education, as well as breastfeeding duration information, were collected with interviewer-administered questionnaires. At 26-28 weeks' gestation, participants came for a clinic visit where their height and weight were measured and BMI was derived. They were also given a self-administered Edinburgh Postnatal Depression Scale (EPDS) questionnaire to fill in to assess their mood. Birth outcomes (eg, birth weight, sex of child and Apgar score) were recorded by midwives at delivery. BMI at the first trimester and GDM treatment were obtained from the medical records.

\section{Statistical analysis}

Independent t-test and $\chi^{2}$ test were used to compare the neonatal and maternal characteristics of participants. Linear regression models were run to assess the associations between (1) maternal blood glucose levels (predictor: fasting or 2-hour post-OGTT) and child anthropometric measurements (outcome: BMI z-scores or sum of skinfold thickness), and (2) maternal blood glucose level(s) (predictor: blood glucose level(s) significantly associated with child anthropometric measurement in (1) and amygdala measurements (outcome: volume or FA), amygdala measurements (predictor: amygdala measurement significantly associated with maternal blood glucose levels in (2) and child anthropometric measurements (outcome: BMI z-scores or sum of skinfold thickness). All regression models were adjusted for ethnicity, maternal age, maternal education, EPDS score and maternal BMI at 26-28 weeks' gestation. Household income was not included in the model due to the high correlation with maternal education. Our group has shown previously ${ }^{58}$ that maternal glycemia was positively associated with offspring birth weight. At the same time, other studies have shown that birth weight is an important marker associated with structural differences throughout the brain, ${ }^{59}$ as well as childhood adiposity and obesity. ${ }^{60}$ Thus, birth weight may potentially lie on the causal pathway between maternal glycemia and child adiposity, as well as between maternal glycemia and neonatal amygdala. Conditioning on birth weight in these analyses could potentially introduce collider-stratification bias ${ }^{61}$; hence, birth weight is not included in the model. For all models involving child anthropometric measurements, only one anthropometric measurement (BMI z-scores or sum of skinfold thickness) was included each time. Likewise, for all models involving maternal 
blood glucose level, only one blood glucose concentration (fasting or 2-hour post-OGTT) was included each time. For models with skinfold thickness as outcomes, sex of the child and age at anthropometric measurement were added as additional covariates. This was not done for models with BMI z-scores as outcomes since the z-scores were already derived based on sex and age at measurement. For models involving amygdala measurements, postconceptual age at MRI visit (gestational age+age at MRI visit) and total brain volume were included as additional covariates. These covariates were chosen because they are known to affect maternal metabolism, amygdala microstructure and/or offspring adiposity. For example, we adjusted for antenatal EPDS as it was previously found by our group to affect the amygdala microstructure. ${ }^{35}$ Before testing for mediation, potential interactions between fasting blood glucose and amygdala measurements on offspring adiposity were checked using the general linear model. Mediation effect by the amygdala was estimated by regression-based mediation ${ }^{62}$ using the PARAMED macro ${ }^{63}$ in STATA version 14 , which uses a counterfactual-based approach to mediation. Data were missing on maternal education in $0.8 \% \quad(n=1)$, antenatal EPDS score in $5.7 \%(n=7)$ and 26 weeks' $\mathrm{BMI}$ in $1.6 \%(\mathrm{n}=2)$ of the participants included in this analysis. Listwise deletion was used to handle missing data. Missing variables were found to be missing completely at random by Little's Missing Completely At Random (MCAR) test. In view of our relatively small sample size, no multiple comparison correction was applied for all analyses to minimize type II error, ${ }^{64}$ to avoid missing out potential important findings.

Sensitivity analyses were done with additional adjustment for GDM treatment and breastfeeding duration, on top of the covariates listed previously. The results were similar and therefore were not presented. All analyses were carried out by using SPSS V.24.0 unless otherwise stated.

\section{Data and resource availlability}

The datasets generated during and/or analyzed during the current study are available from the corresponding author on reasonable request.

\section{RESULTS}

\section{Participant characteristics}

One hundred and twenty-three mother-child dyads were included in this analysis; these participants were comparable with those who did no undergo MRI, in terms of sex distribution of offspring and fasting blood glucose levels (table 1). However, neonates included in this study had greater gestational age, higher birth weight and more likely to be of Malay ethnicity. The mothers were younger, less likely to have university or higher education, and had higher EPDS scores. They also had lower first trimester and late second trimester BMI, lower 2-hour post-OGTT blood glucose levels and were less likely to be diagnosed with GDM. Of the 123 women included in this analysis, 14 were diagnosed with GDM, of which 3 (21.4\%) did not undergo any treatment; $10(71.4 \%)$ had dietary counselling; and $1(7.1 \%)$ received insulin treatment.

\section{Maternal blood glucose levels and childhood adiposity}

We observed that maternal antenatal fasting glucose was positively associated with the offspring's sum of skinfold thickness at age 48 months $(\beta=3.12,95 \%$ CI 0.18 to $6.06 \mathrm{~mm})$ and 60 months $(\beta=4.14,95 \%$ CI 0.46 to $7.82 \mathrm{~mm}$ ) (figure $1 \mathrm{~A}$ ) and BMI z-scores at 48 months $(\beta=0.94,95 \%$ CI 0.27 to 1.61$), 54$ months $(\beta=0.74,95 \%$ CI 0.12 to 1.36$)$ and 60 months $(\beta=0.74,95 \%$ CI 0.08 to 1.39 ) (figure $1 \mathrm{~B}$ ) in offspring of non-obese mothers. A similar positive trend was observed with sum of skinfold thickness at 54 months $(\beta=2.85,95 \%$ CI -0.04 to $5.74 \mathrm{~mm})$. No obvious trends were observed between fasting glucose and childhood adiposity measurements in the earlier time points between 18 and 36 months of age. No significant associations were observed between maternal 2-hour post-OGTT glucose levels and offspring adiposity measures (online supplemental table 1).

\section{Maternal fasting glucose levels and neonatal amygdala microstructure}

The mean and SD of the amygdala volume and FA of the left and right hemispheres are $214 \pm 32 \mathrm{~mm}^{3}$, $0.15 \pm 0.02$, and $187 \pm 32 \mathrm{~mm}^{3}, 0.16 \pm 0.03$, respectively. A higher maternal fasting glucose level was associated with a significantly lower FA of the right amygdala in the offspring (table 2) of non-obese women. A similar trend was observed in the left amygdala FA but did not reach statistical significance (table 2). Maternal fasting glucose was not significantly associated with the amygdala volume (table 2).

\section{Neonatal amygdala FA and childhood adiposity}

Figure 2 shows the association of the right amygdala FA and adiposity measures, including the sum of skinfold thickness (figure 2A) and BMI z-scores (figure 2B) up to 60 months. The neonatal right amygdala FA was negatively associated with the sum of skinfold thickness at 48 months $(\beta=-56.95,95 \%$ CI -98.43 to $-15.47 \mathrm{~mm})$, 54 months $(\beta=-46.18,95 \%$ CI -88.57 to $-3.78 \mathrm{~mm})$ and 60 months $(\beta=-53.69,95 \%$ CI -105.74 to $-1.64 \mathrm{~mm})$ (figure 2A). For BMI z-scores, although there was no significant association, the same negative pattern was observed (figure 2B).

\section{Mediation by the right amygdala FA on maternal fasting glucose-linked childhood adiposity}

Significant interaction was observed between maternal fasting glucose and the right amygdala FA on sum of skinfolds (48 months: $\mathrm{p}=0.005,54$ months: $\mathrm{p}<0.001$, and 60 months: $\mathrm{p}=0.027$ ). This exposure-mediator interaction was taken into consideration in the regression-based mediation. The effect sizes mediated by the right amygdala FA between fasting glucose and sum of skinfolds 
Table 1 Maternal and child characteristics of participants

\begin{tabular}{|c|c|c|c|}
\hline & Participants included $(n=123)$ & Participants excluded $(n=972)$ & $P$ value \\
\hline \multicolumn{4}{|l|}{ Infant variables } \\
\hline Gestational age (weeks) & $39.0 \pm 1.0$ & $38.7 \pm 1.6$ & 0.003 \\
\hline Sex of child (male), $\mathrm{n}(\%)$ & $68(55.3)$ & $504(51.9)$ & 0.473 \\
\hline Birth weight $(g)$ & $3149 \pm 367$ & $3071 \pm 476$ & 0.035 \\
\hline \multicolumn{4}{|l|}{ Ethnicity, n (\%) } \\
\hline Chinese & $60(48.8)$ & $538(55.3)$ & 0.001 \\
\hline Malay & $49(39.8)$ & $242(24.9)$ & \\
\hline Indian & $14(11.4)$ & $192(19.8)$ & \\
\hline \multicolumn{4}{|l|}{ Maternal variables } \\
\hline \multicolumn{4}{|l|}{ Maternal education, n (\%) } \\
\hline Primary/no education & $4(3.3)$ & $41(4.2)$ & 0.014 \\
\hline Secondary & $45(36.6)$ & $251(25.8)$ & \\
\hline Diploma/technical education & $50(40.7)$ & $336(34.6)$ & \\
\hline University and above & $23(18.7)$ & $331(34.0)$ & \\
\hline Missing data & $1(0.8)$ & $15(1.5)$ & \\
\hline Maternal age (years) & $29.4 \pm 5.5$ & $30.6 \pm 5.1$ & 0.013 \\
\hline Antenatal EPDS score & $8.46 \pm 4.27$ & $7.36 \pm 4.54$ & 0.013 \\
\hline Maternal first trimester BMI $\left(\mathrm{kg} / \mathrm{m}^{2}\right)$ & $22.2 \pm 3.5$ & $23.8 \pm 4.9$ & $<0.001$ \\
\hline Maternal 26-28 weeks' BMI $\left(\mathrm{kg} / \mathrm{m}^{2}\right)$ & $25.0 \pm 3.4$ & $26.4 \pm 4.6$ & $<0.001$ \\
\hline Antenatal fasting glucose (mmol/L) & $4.34 \pm 0.39$ & $4.35 \pm 0.46$ & 0.947 \\
\hline Antenatal 2-hour glucose (mmol/L) & $6.09 \pm 1.43$ & $6.57 \pm 1.45$ & 0.001 \\
\hline Diagnosed with GDM, n (\%) & $14(11.4)$ & 185 (19.0) & 0.033 \\
\hline
\end{tabular}

Data presented as mean \pm SD.

BMI, Body Mass Index; EPDS, Edinburgh Postnatal Depression Scale; GDM, gestational diabetes mellitus.

were estimated at $\beta=5.14,95 \%$ CI 0.74 to $9.53 \mathrm{~mm}$ $(\mathrm{p}=0.022) ; \beta=4.40,95 \%$ CI 0.08 to $8.72 \mathrm{~mm}(\mathrm{p}=0.049)$; and $\beta=4.56,95 \%$ CI -0.17 to $9.29 \mathrm{~mm}(\mathrm{p}=0.059)$ at 48,54 and 60 months, respectively (table 3 ). In other words, the effects of $1 \mathrm{mmol} / \mathrm{L}$ change in maternal fasting glucose on offspring skinfolds that are attributed to variations in neonatal amygdala FA are 5.14, 4.40 and $4.56 \mathrm{~mm}$ at ages 48,54 and 60 months, respectively.

The proportions of total effect contributed by the mediator were estimated to be $0.65,0.68$ and 0.52 at 48 ,
A

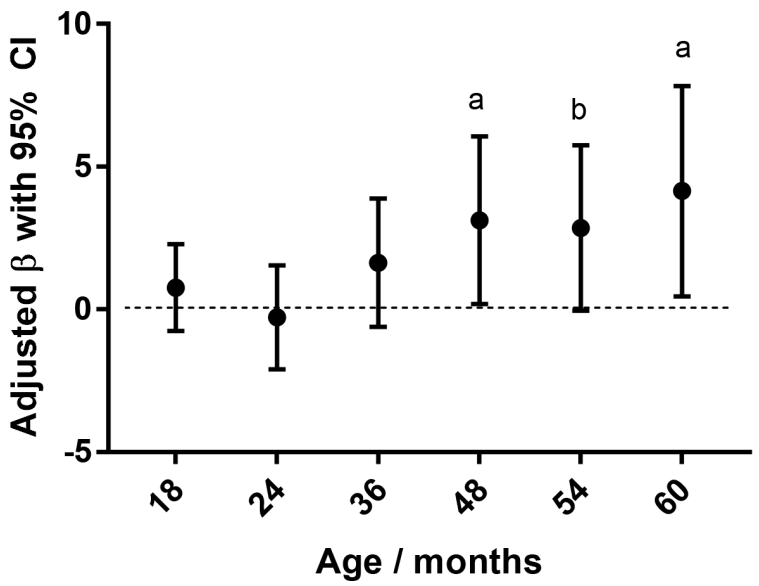

B

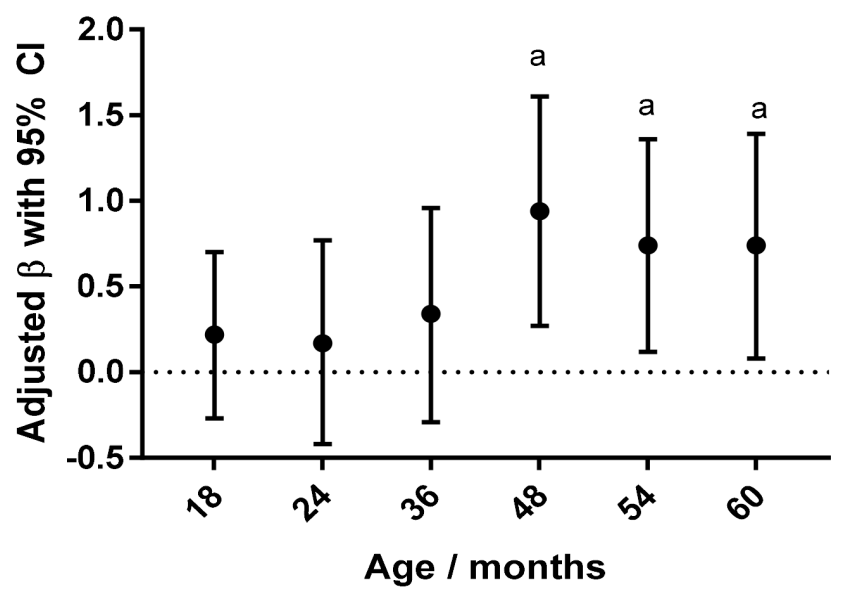

Figure 1 Adjusted regression coefficient (with 95\% Cl) of maternal antenatal fasting blood glucose levels (per $1 \mathrm{mmol} / \mathrm{L}$ ) on child adiposity measures in the first 60 months of life for offspring of non-obese mothers. (A) Sum of skinfolds (triceps and subscapular) (mm) and (B) Body Mass Index z-scores. ${ }^{\mathrm{a}} \mathrm{P}<0.05,{ }^{\mathrm{b}} \mathrm{P}<0.10$. 
Table 2 Associations of maternal antenatal fasting blood glucose concentrations with volume and FA of the neonatal amygdala in offspring born to non-obese women

\begin{tabular}{lrcc}
\hline All participants & $\mathbf{N}$ & Unadjusted $\boldsymbol{\beta}$ (95\% Cl) & Adjusted $\boldsymbol{\beta}^{\boldsymbol{*}}(\mathbf{9 5 \%} \mathbf{C l})$ \\
\hline Left amygdala FA & 89 & $-0.007(-0.016$ to 0.003$)$ & $-0.005(-0.018$ to 0.007$)$ \\
Right amygdala FA & 89 & $-0.023(-0.037$ to -0.009$)$ & $-0.019(-0.036$ to -0.003$)$ \\
Left amygdala volume $\left(\mathrm{mm}^{3}\right)$ & 123 & $9.68(-4.93$ to 24.29$)$ & $5.48(-12.69$ to 23.64$)$ \\
Right amygdala volume $\left(\mathrm{mm}^{3}\right)$ & 123 & $3.59(-11.24$ to 18.42$)$ & $3.36(-14.96$ to 21.70$)$ \\
\hline
\end{tabular}

Data presented as unstandardized $\beta$ (95\% Cl).

${ }^{*}$ Adjusted for postconceptual age at MRI, ethnicity, sex of child, maternal age, maternal education, 26 weeks Edinburgh Postnatal

Depression Scale score, total brain volume and maternal Body Mass Index at 26 weeks.

FA, fractional anisotropy.

54 and 60 months, respectively (table 3 ). No significant mediation by the right amygdala FA was found between fasting glucose and BMI z-scores score up to 60 months of age, although a marginal trend was observed at 54 months with $\beta=0.47$ (95\% CI -0.09 to 1.03 ) ( $\mathrm{p}=0.097$ ) (table 3).

\section{DISCUSSION}

We found that higher maternal antenatal fasting glucose concentrations were associated with increased sum of skinfolds in the offspring of non-obese Asian women, at 48 and 60 months, as well as higher offspring BMI z-scores at 48, 54 and 60 months. Increased maternal antenatal fasting glucose concentrations were also correlated with lower FA in the right amygdala. The right amygdala FA was, in turn, negatively associated with offspring skinfold thicknesses from 48 months onwards. Mediation analyses suggest that right amygdala FA may be a potential mediator in the pathway between maternal antenatal fasting glucose and offspring adiposity as measured by the sum of skinfold thicknesses.

The amygdala is linked to food intake and obesity. ${ }^{21} 2265$ The human amygdala is known to respond to food cues, ${ }^{667}$

A

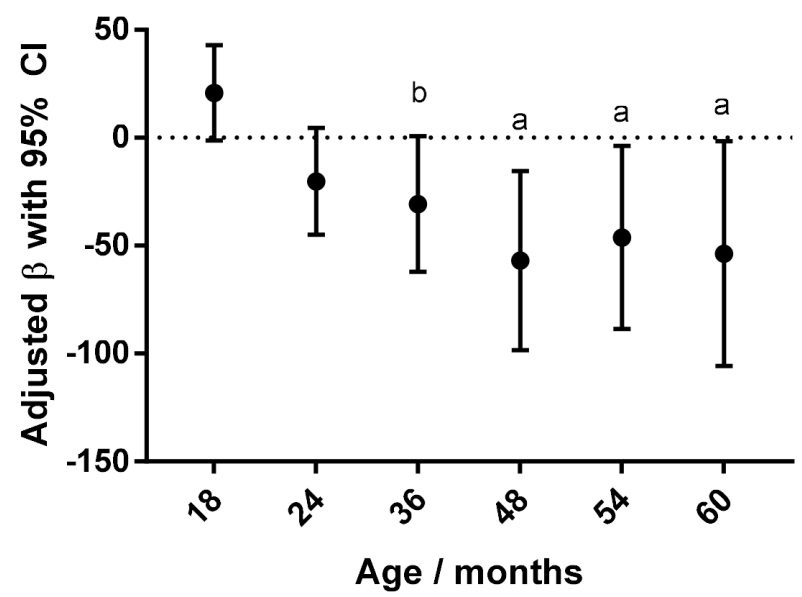

and amygdala responses have been associated with subsequent consumption of high-fat food. ${ }^{68}$ Amygdala volume has also been associated with fat intake ${ }^{27}$ in adolescents and BMI in young adults ${ }^{28}$ and children, ${ }^{23}{ }^{24}$ while increased amygdala connectivity with ventromedial prefrontal cortex has been observed in lean individuals compared with obese adult participants. ${ }^{31}$ Greater neonatal right amygdala volume and connectivity have also been associated with lower impulse control for a snack delay task at 2 years of age. ${ }^{26}$ fMRI of obese children showed hyper-responsiveness to food rewards in their amygdala compared with normal-weight children. ${ }^{29}$ Lower FA has been previously reported in many brain regions of obese individuals (elderly, adults and children), ${ }^{69}$ including brain regions involved in appetite, inhibitory control and reward such as amygdala. ${ }^{71}$ While a couple of studies have observed a positive association between both right and left amygdala volume and BMI or obesity, ${ }^{24} 72$ we found a correlation only with the right side of the amygdala, similar to Orsi $e t a l^{28}$ who reported a correlation between the right amygdala volume and BMI. Another study also showed right amygdala volume and connectivity to be linked to poorer impulse control

B

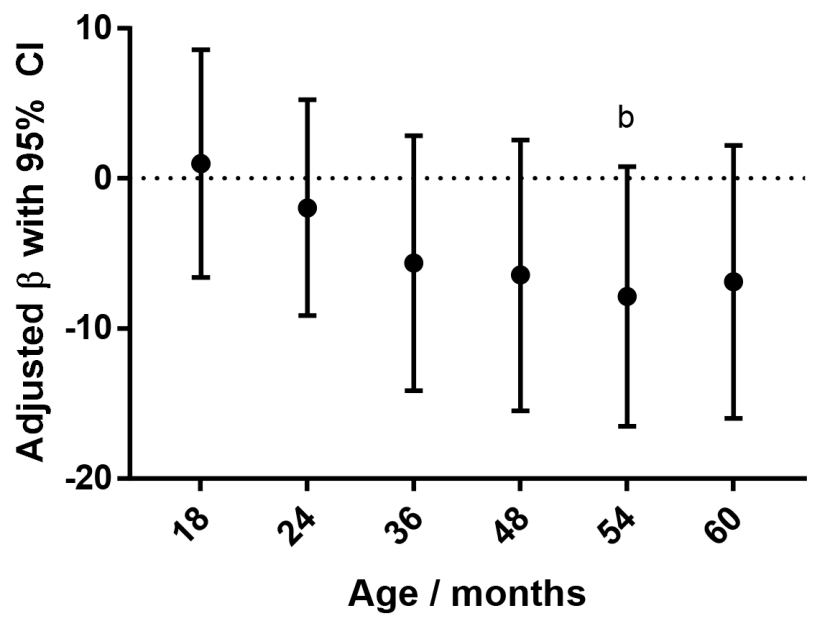

Figure 2 Adjusted regression coefficient (with 95\% Cl) of neonatal right amygdala fractional anisotropy on child adiposity measures in the first 60 months of life for offspring of non-obese mothers. (A) Sum of skinfolds (triceps and subscapular) (mm) and $(\mathrm{B})$ Body Mass Index z-scores. ${ }^{\mathrm{a}} \mathrm{P}<0.05,{ }^{\mathrm{b}} \mathrm{P}<0.10$. 
Table 3 Estimated effect mediated by neonatal right amygdala FA in the association between antenatal fasting blood glucose and offspring adiposity

\begin{tabular}{|c|c|c|c|c|c|c|}
\hline \multirow[b]{2}{*}{ Age (months) } & \multicolumn{3}{|l|}{ Sum of skinfolds } & \multicolumn{3}{|l|}{ BMI z-scores } \\
\hline & $\beta(95 \% \mathrm{Cl})$ & $P$ value & $\begin{array}{l}\text { Proportion of total } \\
\text { effect }^{\star}\end{array}$ & $\beta(95 \% \mathrm{Cl})$ & $P$ value & $\begin{array}{l}\text { Proportion of } \\
\text { total effect }\end{array}$ \\
\hline 48 & 5.14 (0.74 to 9.53$)$ & 0.022 & 0.65 & $0.39(-0.17$ to 0.95$)$ & 0.171 & 0.42 \\
\hline 54 & 4.40 (0.08 to 8.72$)$ & 0.049 & 0.68 & $0.47(-0.09$ to 0.57$)$ & 0.097 & 0.57 \\
\hline 60 & $4.56(-0.17$ to 9.29$)$ & 0.059 & 0.52 & $0.46(-0.12$ to 1.03$)$ & 0.123 & 0.52 \\
\hline
\end{tabular}

Data presented as unstandardized $\beta(95 \% \mathrm{Cl})$.

*Proportion of effect mediated by neonatal right amygdala FA compared with total effects of antenatal fasting glucose on offspring adiposity.

BMI, body mass index; FA, fractional anisotropy.

for a food task in 2-year-old toddlers. ${ }^{26}$ Although we do not have a full explanation of the lateralization differences, differences in hemispheric processing between left and right amygdalae have been previously suggested in humans ${ }^{73}$ and animals. ${ }^{74}$ van der Laan et al ${ }^{75}$ found that hunger modifies the activation of the right amygdala towards images of food.

Overall, while we observed a similar trend with both measurements of adiposity, we had more consistent findings with the sum of skinfolds, which is a surrogate for total adiposity. BMI has been regarded as a more crude measurement of adiposity as it can be influenced by fat free mass, especially in children. ${ }^{76} \mathrm{It}$ is noteworthy that previous studies showed associations between the amygdala and BMI in adolescents or older adults. ${ }^{27} 2831$

Our group ${ }^{8}$ and others ${ }^{77}$ previously reported higher antenatal fasting glucose to be associated with greater adiposity in children, particularly those born to non-obese mothers. In fact, our group has also examined longitudinal effect of antenatal fasting glucose on weight and BMI trajectory in the offspring and has shown that higher antenatal fasting glucose is positively associated with weight and BMI trajectory in the first 36 months among offspring of non-obese mothers. ${ }^{8}$ We did not observe a significant association between 2-hour post OGTT glucose and offspring adiposity, possibly because of the large variation in 2-hour OGTT glucose; hence, there was a likelihood of larger errors. Moreover, 2-hour OGTT blood glucose may be attenuated through exaggerated glucose steal due to fetal hyperinsulinemia, ${ }^{78}$ a condition in the offspring of mothers with hyperglycemia, which is also a driver of fetal fat accretion. As a result, some mothers may have 'normal' glucose tolerance even though their offspring may exhibit diabetic fetopathy. ${ }^{78}$ Maternal obesity and hyperglycemia share common biological pathways such as state of inflammation, impairment in regulation of energy and excess of fuel substrates. ${ }^{48} 49$ Hence, maternal obesity may reduce the independent association observed between maternal glycemia and offspring adiposity. Our results also showed that significant differences in maternal glycemia associated offspring become apparent from 48 months of age onwards. This is consistent with earlier reports of null findings at 2 years of age $\mathrm{e}^{79}$ and a study of women with overt diabetes during pregnancy, where the maternal hyperglycemia-related obesity resolved within first 1-2years of life. ${ }^{80}$ Many studies showed that the association between maternal diabetes and offspring obesity recurs at a later part of childhood. ${ }^{581-83}$ This is not surprising if food intake and response to food cues are involved. During infancy and toddlerhood, food choices and portion size are largely determined by parents and caregivers, while older children have more autonomy in food choices and portion sizes when they start attending preschool.

The prospective nature of our study is a strength as we examined the association of in utero glucose exposure on the microstructure of the neonatal amygdala and subsequent adiposity in toddlerhood and early childhood. We are also, to the best of our knowledge, among the first to study the mediating role of differences in the amygdala, in the pathway between maternal glycemia and offspring adiposity. Another strength of our study is the large number of covariates considered, including maternal mental wellbeing. A limitation of our study is the small number of participants, which limited our statistical power. Replication of this study with a larger sample size is necessary. We also recognize that the blood glucose levels were measured once during pregnancy and may not be representative of the in utero exposure throughout pregnancy, especially post-GDM diagnosis and treatment. Insulin levels were also not measured during the OGTT; as such, we were unable to study maternal insulin sensitivity in relation to neonatal amygdala or child adiposity. We acknowledge that a large number of outcomes were investigated and we did not adjust for multiple comparisons; hence, we cannot rule out the possibility of chance findings. However, the findings were in the same direction for both BMI z-scores and sum of skinfolds and consistently at similar time points. We acknowledge that there could be potential selection bias in the participants who agreed to undergo the MRI and were included in this study. For example, they were more likely to be older, have lower education, more depressed and of lower BMI. However, these factors were adjusted, where appropriate, in our analysis.

\section{CONCLUSIONS}

Our study shows that maternal blood glucose level during pregnancy is associated with early childhood adiposity, 
and this may be mediated by differences in the microstructure of the amygdala, a brain structure implicated in feeding behaviors. These findings provide a novel pathway by which antenatal maternal blood glucose might influence the later risk of adiposity in the offspring.

\section{Author affiliations}

'Singapore Institute for Clinical Sciences, Agency for Science Technology and Research, Singapore

2Department for Obstetrics and Gynaecology, Yong Loo Lin School of Medicine, National University of Singapore, Singapore

${ }^{3}$ Division of Chronic Disease Research Across the Lifecourse, Department of Population Medicine, Harvard Medical School and Harvard Pilgrim Health Care Institute, Boston, Massachusetts, USA

${ }^{4}$ Department of Paediatrics, Yong Loo Lin School of Medicine, National University of Singapore, Singapore

${ }^{5}$ Department of Maternal Fetal Medicine, KK Women's and Children's Hospital, Singapore

${ }^{6}$ Duke-NUS Medical School, Singapore

${ }^{7}$ MRC Lifecourse Epidemiology Unit, University of Southampton, Southampton, UK ${ }^{8}$ NIHR Southampton Biomedical Research Centre, University Hospital Southampton NHS Foundation Trust, Southampton, UK

${ }^{9}$ The Liggins Institute, The University of Auckland, Aukland, New Zealand

${ }^{10}$ Department of Pediatric Endocrinology, KK Women's and Children's Hospital, Singapore

${ }^{11}$ Department of Diagnostic and Interventional Imaging, KK Women's and Children's Hospital, Singapore

${ }^{12}$ Departments of Psychiatry and Neurology and Neurosurgery, McGill University, Montreal, Québec, Canada

${ }^{13}$ Department of Biomedical Engineering, National University of Singapore, Singapore

Acknowledgements We thank the staff and participants of the Growing Up in Singapore Towards Healthy Outcomes (GUSTO) study as well as members of the GUSTO study group. The GUSTO study group includes Allan Sheppard, Amutha Chinnadurai, Anne Eng Neo Goh, Anne Rifkin-Graboi, Arijit Biswas, Bee Wah Lee, Birit F.P. Broekman, Boon Long Quah, Borys Shuter, Chai Kiat Chng, Cheryl Ngo, Choon Looi Bong, Christiani Jeyakumar Henry, Cornelia Yin Ing Chee, Yam Thiam Daniel Goh, Doris Fok, Fabian Yap, George Seow Heong Yeo, Helen Chen, Hugo P $S$ van Bever, lliana Magiati, Inez Bik Yun Wong, Ivy Yee-Man Lau, Jeevesh Kapur, Jenny L. Richmond, Jerry Kok Yen Chan, Joanna D. Holbrook, Joshua J. Gooley, Keith M. Godfrey, Kenneth Kwek, Krishnamoorthy Niduvaje, Leher Singh, Lin Lin Su, Lourdes Mary Daniel, Mark Hanson, Mary Foong-Fong Chong, Mary Rauff, Mei Chien Chua, Mya Thway Tint, Neerja Karnani, Ngee Lek, Oon Hoe Teoh, P. C. Wong, Pratibha Agarwal, Rob M. van Dam, Salome A. Rebello, Seang-Mei Saw, Shang Chee Chong, Shu-E Soh, Sok Bee Lim, Chin Ying Stephen Hsu, Victor Samuel Rajadurai, Walter Stunkel, Wee Meng Han, Wei Wei Pang, Yin Bun Cheung and Yiong Huak Chan

Contributors SC and $\mathrm{AQ}$ conceptualized the idea, analyzed the data and wrote the manuscript. All the other authors were involved in supervision of data collection, derivation/cleaning of the data and/or design of the cohort study. SC performed the statistical analysis for the paper and takes responsibility for the accuracy of the analysis. All authors critically reviewed the manuscript. $A Q$ had full access to all of the data in the study and takes responsibility for the integrity of the data. $A Q$ is the guarantor of this article.

Funding This research is supported by the Singapore National Research Foundation under its Translational and Clinical Research (TCR) Flagship Programme and administered by the Singapore Ministry of Health's National Medical Research Council (NMRC), Singapore - NMRC/TCR/004-NUS/2008; NMRC/ TCR/012-NUHS/2014. Additional funding is provided by the Singapore Institute for Clinical Sciences, Agency for Science Technology and Research, Singapore. The funding organizations had no role in the design and conduct of the study; collection, management, analysis and interpretation of the data; preparation, review or approval of the manuscript; and the decision to submit the manuscript for publication.

Competing interests PDG, KMG, and Y-SC have received lecture fees from companies that sell nutritional products. They are part of an academic consortium that has received research funding from Abbott Nutrition, Nestec, and Danone. KMG is supported by the UK Medical Research Council (MC_UU_12011/4), the National Institute for Health Research (NIHR Senior Investigator (NF-SI-0515-10042) and the NIHR Southampton Biomedical Research Centre) and the European Union (Erasmus+ Programme Early Nutrition eAcademy Southeast Asia-573651-EPP-12016-1-DE-EPPKA2-CBHE-JP). The other authors have nothing to disclose.

\section{Patient consent for publication Not required.}

Ethics approval This study was approved by the institutional review board of the Singapore National Healthcare Group (B/2014/00411) and the centralized institutional review board of SingHealth (2009/785/A).

Provenance and peer review Not commissioned; externally peer reviewed.

Data availability statement Data are available upon reasonable request

Supplemental material This content has been supplied by the author(s). It has not been vetted by BMJ Publishing Group Limited (BMJ) and may not have been peer-reviewed. Any opinions or recommendations discussed are solely those of the author(s) and are not endorsed by BMJ. BMJ disclaims all liability and responsibility arising from any reliance placed on the content. Where the content includes any translated material, BMJ does not warrant the accuracy and reliability of the translations (including but not limited to local regulations, clinical guidelines, terminology, drug names and drug dosages), and is not responsible for any error and/or omissions arising from translation and adaptation or otherwise.

Open access This is an open access article distributed in accordance with the Creative Commons Attribution Non Commercial (CC BY-NC 4.0) license, which permits others to distribute, remix, adapt, build upon this work non-commercially, and license their derivative works on different terms, provided the original work is properly cited, appropriate credit is given, any changes made indicated, and the use is non-commercial. See: http://creativecommons.org/licenses/by-nc/4.0/.

\section{ORCID iDs}

Izzuddin M Aris http://orcid.org/0000-0002-9239-7476

Wen Lun Yuan http://orcid.org/0000-0002-7472-5042

Keith M Godfrey http://orcid.org/0000-0002-4643-0618

Peter D Gluckman http://orcid.org/0000-0002-5711-1655

Yung Seng Lee http://orcid.org/0000-0002-1253-0557

Anqi Qiu http://orcid.org/0000-0002-0215-6338

\section{REFERENCES}

1 Bell R, Bailey K, Cresswell T. Northern diabetic pregnancy survey steering G: trends in prevalence and outcomes of pregnancy in women with pre-existing type I and type II diabetes. BJOG 2008;115:445-52.

$2 \mathrm{Ng} \mathrm{M}$, Fleming T, Robinson M, et al. Global, regional, and national prevalence of overweight and obesity in children and adults during 1980-2013: a systematic analysis for the global burden of disease study 2013. The Lancet 2014;384:766-81.

3 Pedersen J. The pregnant diabetic and her newborn: problems and management. Baltimore: Williams \& Wilkins, 1977.

4 Kubo A, Ferrara A, Windham GC, et al. Maternal hyperglycemia during pregnancy predicts adiposity of the offspring. Diabetes Care 2014;37:2996-3002.

5 Pettitt DJ, Baird HR, Aleck KA, et al. Excessive obesity in offspring of Pima Indian women with diabetes during pregnancy. New England Journal of Medicine 1983;308:242-5.

6 Pettitt DJ, Knowler WC, Bennett PH, et al. Obesity in offspring of diabetic Pima Indian women despite normal birth weight. Diabetes Care 1987;10:76-80.

7 Zhu Y, Olsen SF, Mendola P, et al. Growth and obesity through the first $7 Y$ of life in association with levels of maternal glycemia during pregnancy: a prospective cohort study. Am J Clin Nutr 2016;103:794-800.

8 Aris IM, Soh SE, Tint MT, et al. Associations of gestational glycemia and prepregnancy adiposity with offspring growth and adiposity in an Asian population. Am J Clin Nutr 2015;102:1104-12.

9 Ehrlich SF, Rosas LG, Ferrara A, et al. Pregnancy glycemia in Mexican-American women without diabetes or gestational diabetes and programming for childhood obesity. Am J Epidemiol 2013;177:768-75.

10 Lillycrop K, Murray R, Cheong C, et al. Anril promoter DNA methylation: a perinatal marker for later adiposity. EBioMedicine 2017:19:60-72.

11 Lin X, Lim IY, Wu Y, et al. Developmental pathways to adiposity begin before birth and are influenced by genotype, prenatal environment and epigenome. BMC Med 2017;15:50. 
12 Rasmussen JM, Entringer S, Kruggel F, et al. Newborn insula gray matter volume is prospectively associated with early life adiposity gain. Int J Obes 2017;41:1434-9.

13 Ou X, Thakali KM, Shankar K, et al. Maternal adiposity negatively influences infant brain white matter development. Obesity 2015;23:1047-54.

14 Könner AC, Klöckener T, Brüning JC. Control of energy homeostasis by insulin and leptin: targeting the arcuate nucleus and beyond. Physiol Behav 2009;97:632-8.

15 Mietus-Snyder ML. Lustig RH: Childhood obesity: adrift in the "limbic triangle". Annu Rev Med 2008;59:147-62.

16 Velloso LA, Schwartz MW. Altered hypothalamic function in dietinduced obesity. Int J Obes 2011;35:1455-65.

17 Schoenfeld TA, Hamilton LW. Disruption of appetite but not hunge or satiety following small lesions in the amygdala of rats. J Comp Physiol Psychol 1981;95:565-87.

18 King BM, Sam H, Arceneaux ER, et al. Effect on food intake and body weight of lesions in and adjacent to the posterodorsal amygdala in rats. Physiol Behav 1994;55:963-6.

19 King BM, Cook JT, Rossiter KN, et al. Obesity-inducing amygdala lesions: examination of anterograde degeneration and retrograde transport. Am J Physiol Regul Integr Comp Physiol 2003;284:R965-82.

20 Rollins BL, King BM. Amygdala-lesion obesity: what is the role of the various amygdaloid nuclei? Am J Physiol Regul Integr Comp Physiol 2000;279:R1348-56.

21 Areias MFC, Prada PO. Mechanisms of insulin resistance in the amygdala: influences on food intake. Behav Brain Res 2015;282:209-17

22 Carnell S, Gibson C, Benson L, et al. Neuroimaging and obesity: current knowledge and future directions. Obesity Reviews 2012;13:43-56.

$23 \mathrm{Kim}$ MS, Luo S, Azad A, et al. Prefrontal cortex and amygdala subregion morphology are associated with obesity and dietary self-control in children and adolescents. Front Hum Neurosci 2020;14:563415.

24 Perlaki G, Molnar D, Smeets PAM, et al. Volumetric gray matter measures of amygdala and accumbens in childhood overweight/ obesity. PLoS One 2018;13:e0205331.

25 Adise S, Geier CF, Roberts NJ, et al. Is brain response to food rewards related to overeating? A test of the reward surfeit model of overeating in children. Appetite 2018;128:167-79.

26 Graham AM, Rasmussen JM, Rudolph MD, et al. Maternal systemic interleukin-6 during pregnancy is associated with newborn amygdala phenotypes and subsequent behavior at 2 years of age. Biol Psychiatry 2018;83:109-19.

27 Haghighi A, Schwartz DH, Abrahamowicz M, et al. Prenatal exposure to maternal cigarette smoking, amygdala volume, and fat intake in adolescence. JAMA Psychiatry 2013;70:98-105.

28 Orsi G, Perlaki G, Kovacs N, et al. Body weight and the reward system: the volume of the right amygdala may be associated with body mass index in young overweight men. Brain Imaging Behav 2011;5:149-57.

29 Boutelle KN, Wierenga CE, Bischoff-Grethe A, et al. Increased brain response to appetitive tastes in the insula and amygdala in obese compared with healthy weight children when sated. Int $J$ Obes 2015;39:620-8.

30 Schur EA, Melhorn SJ, Scholz K, et al. Child neurobiology impacts success in family-based behavioral treatment for children with obesity. Int J Obes 2020;44:2011-22.

31 Wijngaarden MA, Veer IM, Rombouts SARB, et al. Obesity is marked by distinct functional connectivity in brain networks involved in food reward and salience. Behav Brain Res 2015;287:127-34.

32 Lupien SJ, McEwen BS, Gunnar MR, et al. Effects of stress throughout the lifespan on the brain, behaviour and cognition. Nat Rev Neurosci 2009;10:434-45.

33 Tottenham N, Sheridan MA. A review of adversity, the amygdala and the hippocampus: a consideration of developmental timing. Front Hum Neurosci 2009;3:68.

34 Qiu A, Anh TT, Li Y, et al. Prenatal maternal depression alters amygdala functional connectivity in 6-Month-Old infants. Trans/ Psychiatry 2015;5:e508.

35 Rifkin-Graboi A, Bai J, Chen H, et al. Prenatal maternal depression associates with microstructure of right amygdala in neonates at birth. Biol Psychiatry 2013;74:837-44.

36 Sells CJ, Robinson NM, Brown Z, et al. Long-Term developmental follow-up of infants of diabetic mothers. J Pediatr 1994;125:S9-17.

37 Ornoy A, Ratzon N, Greenbaum C, et al. School-Age children born to diabetic mothers and to mothers with gestational diabetes exhibit a high rate of inattention and fine and gross motor impairment. $J$ Pediatr Endocrinol Metab 2001;14 Suppl 1:681-9.
38 DeBoer T, Wewerka S, Bauer PJ, et al. Explicit memory performance in infants of diabetic mothers at 1 year of age. Dev Med Child Neurol 2005;47:525-31.

39 deRegnier R-A, Nelson CA, Thomas KM, et al. Neurophysiologic evaluation of auditory recognition memory in healthy newborn infants and infants of diabetic mothers. J Pediatr 2000;137:777-84

40 Nelson CA, Wewerka SS, Borscheid AJ, et al. Electrophysiologic evidence of impaired cross-modal recognition memory in 8-month-old infants of diabetic mothers. J Pediatr 2003:142:575-82

41 Nold JL, Georgieff MK. Infants of diabetic mothers. Pediatr Clin North Am 2004:51:619-37.

42 Page KA, Luo S, Wang X, et al. Children exposed to maternal obesity or gestational diabetes mellitus during early fetal development have hypothalamic alterations that predict future weight gain. Diabetes Care 2019;42:1473-80.

43 Linder K, Schleger F, Kiefer-Schmidt I, et al. Gestational diabetes impairs human fetal postprandial brain activity. J Clin Endocrinol Metab 2015;100:4029-36.

44 Linder K, Schleger F, Ketterer C, et al. Maternal insulin sensitivity is associated with oral glucose-induced changes in fetal brain activity. Diabetologia 2014;57:1192-8.

45 Jorgenson LA, Wobken JD, Georgieff MK. Perinatal iron deficiency alters apical dendritic growth in hippocampal CA1 pyramidal neurons. Dev Neurosci 2003;25:412-20.

46 Rao R, Tkac I, Townsend EL, et al. Perinatal iron deficiency alters the neurochemical profile of the developing rat hippocampus. J Nutr 2003;133:3215-21.

47 Dubois J, Dehaene-Lambertz G, Perrin M, et al. Asynchrony of the early maturation of white matter bundles in healthy infants: quantitative landmarks revealed noninvasively by diffusion tensor imaging. Hum Brain Mapp 2008;29:14-27.

48 King JC. Maternal obesity, metabolism, and pregnancy outcomes. Annu Rev Nutr 2006;26:271-91.

49 Kitajima M, Oka S, Yasuhi I, et al. Maternal Serum Triglyceride at 24-32 Weeks' Gestation and Newborn Weight in Nondiabetic Women With Positive Diabetic Screens. Obstetrics \& Gynecology 2001:97:776-80.

50 Soh S-E, Tint MT, Gluckman PD, et al. Cohort profile: growing up in Singapore towards healthy outcomes (GUSTO) birth cohort study. Int J Epidemiol 2014;43:1401-9.

51 Tint MT, Fortier MV, Godfrey KM, et al. Abdominal adipose tissue compartments vary with ethnicity in Asian neonates: growing up in Singapore toward healthy outcomes birth cohort study. Am J Clin Nutr 2016;103:1311-7.

52 Qiu A, Fortier MV, Bai J, et al. Morphology and microstructure of subcortical structures at birth: a large-scale Asian neonatal neuroimaging study. Neuroimage 2013;65:315-23.

53 Alberti KG, Zimmet PZ. Definition, diagnosis and classification of diabetes mellitus and its complications. Part 1: diagnosis and classification of diabetes mellitus provisional report of a who consultation. Diabet Med 1998;15:539-53.

54 Fischl B, Salat DH, Busa E, et al. Whole brain segmentation: automated labeling of neuroanatomical structures in the human brain. Neuron 2002;33:341-55.

55 Huang $\mathrm{H}$, Ceritoglu C, Li X, et al. Correction of B0 susceptibility induced distortion in diffusion-weighted images using largedeformation diffeomorphic metric mapping. Magn Reson Imaging 2008;26:1294-302

56 Aris IM, Bernard JY, Chen L-W, et al. Postnatal height and adiposity gain, childhood blood pressure and prehypertension risk in an Asian birth cohort. Int J Obes 2017;41:1011-7.

57 WHO. WHO Anthro for personal computers, version 3.2.2, 2011: Software for assessing growth and development of the world's children., 2010. Available: http://www.who.int/childgrowth/software/ en/

58 Aris IM, Soh SE, Tint MT, et al. Effect of maternal glycemia on neonatal adiposity in a multiethnic Asian birth cohort. J Clin Endocrinol Metab 2014;99:240-7.

59 Walhovd KB, Fjell AM, Brown TT, et al. Long-Term influence of normal variation in neonatal characteristics on human brain development. Proc Natl Acad Sci U S A 2012;109:20089-94.

60 Martorell R, Stein AD, Schroeder DG. Early nutrition and later adiposity. J Nutr 2001;131:874S-80.

61 Greenland S. Quantifying biases in causal models: classical confounding vs Collider-Stratification bias. Epidemiology 2003;14:300-6.

62 Valeri L, VanderWeele TJ. Mediation analysis allowing for exposuremediator interactions and causal interpretation: theoretical assumptions and implementation with SAS and SPSS macros. Psychol Methods 2013;18:137-50. 
63 Dunn G, Emsley R, Liu H, et al. Evaluation and validation of social and psychological markers in randomised trials of complex interventions in mental health: a methodological research programme. Health Technol Assess 2015;19:1-116.

64 Rothman KJ. No adjustments are needed for multiple comparisons. Epidemiology 1990;1:43-6.

65 Coppin G. The anterior medial temporal lobes: their role in food intake and body weight regulation. Physiol Behav 2016;167:60-70.

66 O'Doherty JP, Deichmann R, Critchley HD, et al. Neural responses during anticipation of a primary taste reward. Neuron 2002;33:815-26.

67 Small DM, Veldhuizen MG, Felsted J, et al. Separable substrates for anticipatory and consummatory food chemosensation. Neuron 2008;57:786-97.

68 Mehta S, Melhorn SJ, Smeraglio A, et al. Regional brain response to visual food cues is a marker of satiety that predicts food choice. Am $J$ Clin Nutr 2012;96:989-99.

69 Kullmann S, Schweizer F, Veit R, et al. Compromised white matter integrity in obesity. Obesity Reviews 2015;16:273-81.

70 Samara A, Murphy T, Strain J, et al. Neuroinflammation and white matter alterations in obesity assessed by diffusion basis spectrum imaging. Front Hum Neurosci 2019;13:464.

71 Karlsson HK, Tuulari JJ, Hirvonen J, et al. Obesity is associated with white matter atrophy: a combined diffusion tensor imaging and voxel-based morphometric study. Obesity 2013;21:2530-7.

72 Widya RL, de Roos A, Trompet S, et al. Increased amygdalar and hippocampal volumes in elderly obese individuals with or at risk of cardiovascular disease. Am J Clin Nutr 2011;93:1190-5.

73 Markowitsch HJ. Differential contribution of right and left amygdala to affective information processing. Behav Neurol 1998;11:233-44.
74 Baker KB, Kim JJ. Amygdalar lateralization in fear conditioning: evidence for greater involvement of the right amygdala. Behav Neurosci 2004;118:15-23.

75 van der Laan LN, de Ridder DTD, Viergever MA, et al. The first taste is always with the eyes: a meta-analysis on the neural correlates of processing visual food cues. Neuroimage 2011;55:296-303.

76 Wells JCK. A Hattori chart analysis of body mass index in infants and children. Int J Obes 2000;24:325-9.

77 Li W, Wang L, Li N, et al. Maternal prepregnancy BMl and glucose level at 24-28 gestational weeks on offspring's overweight status within 3 years of age. Biomed Res Int 2017;2017:7607210.

78 Desoye G, Nolan CJ. The fetal glucose steal: an underappreciated phenomenon in diabetic pregnancy. Diabetologia 2016;59:1089-94

79 Pettitt DJ, McKenna S, McLaughlin C, et al. Maternal glucose at 28 weeks of gestation is not associated with obesity in 2-yearold offspring: the Belfast hyperglycemia and adverse pregnancy outcome (HAPO) family study. Diabetes Care 2010;33:1219-23.

80 Silverman BL, Rizzo T, Green OC, et al. Long-term prospective evaluation of offspring of diabetic mothers. Diabetes 1991;40:121-5.

81 Dabelea D, Hanson RL, Lindsay RS, et al. Intrauterine exposure to diabetes conveys risks for type 2 diabetes and obesity: a study of discordant sibships. Diabetes 2000;49:2208-11.

82 Hakanen T, Saha MT, Salo MK, et al. Mothers with gestational diabetes are more likely to give birth to children who experience early weight problems. Acta Paediatr 2016;105:1166-72.

83 Silverman BL, Landsberg L, Metzger BE. Fetal hyperinsulinism in offspring of diabetic mothers. association with the subsequent development of childhood obesity. Ann N Y Acad Sci 1993;699:36-45. 